\title{
The Relationship Between Help-Seeking Attitudes and Masculine Norms Among Monozygotic Male-Twins Discordant for Sexual Orientation
}

SUPPLEMENTAL MATERIAL

Online Table S1

Additional Sample Demographic Data

\begin{tabular}{|c|c|c|c|c|c|c|}
\hline & \multicolumn{2}{|c|}{ Whole Sample } & \multicolumn{2}{|c|}{ Gay } & \multicolumn{2}{|c|}{ Heterosexual } \\
\hline & $N$ & $\%$ & $n$ & $\%$ & $n$ & $\%$ \\
\hline \multicolumn{7}{|l|}{ Education } \\
\hline High School or Equivalent & 6 & $7.9 \%$ & 2 & $5.3 \%$ & 4 & $10.5 \%$ \\
\hline Technical School & 1 & $1.3 \%$ & 1 & $2.6 \%$ & 0 & $0.0 \%$ \\
\hline Some College & 8 & $10.5 \%$ & 4 & $10.5 \%$ & 4 & $10.5 \%$ \\
\hline Associates & 4 & $5.3 \%$ & 2 & $5.3 \%$ & 2 & $5.3 \%$ \\
\hline Bachelors & 37 & $48.7 \%$ & 20 & $52.6 \%$ & 17 & $44.7 \%$ \\
\hline Masters/Doctorate & 20 & $26.3 \%$ & 9 & $23.7 \%$ & 11 & $28.9 \%$ \\
\hline \multicolumn{7}{|l|}{ Annual Individual Income } \\
\hline$<\$ 10,000$ & 5 & $6.6 \%$ & 3 & $7.9 \%$ & 2 & $5.3 \%$ \\
\hline$\$ 10-19,999$ & 4 & $5.3 \%$ & 3 & $7.9 \%$ & 1 & $2.6 \%$ \\
\hline$\$ 20-29,999$ & 2 & $2.6 \%$ & 0 & $0.0 \%$ & 2 & $5.3 \%$ \\
\hline$\$ 30-39,999$ & 8 & $10.5 \%$ & 3 & $7.9 \%$ & 5 & $13.2 \%$ \\
\hline$\$ 40-49,999$ & 11 & $14.5 \%$ & 5 & $13.2 \%$ & 6 & $15.8 \%$ \\
\hline$\$ 50-59,999$ & 13 & $17.1 \%$ & 6 & $15.8 \%$ & 7 & $18.4 \%$ \\
\hline$\$ 60-69,999$ & 8 & $10.5 \%$ & 6 & $15.8 \%$ & 2 & $5.3 \%$ \\
\hline$\$ 70-79,999$ & 2 & $2.6 \%$ & 1 & $2.6 \%$ & 1 & $2.6 \%$ \\
\hline$\$ 80-89,999$ & 6 & $7.9 \%$ & 3 & $7.9 \%$ & 3 & $7.9 \%$ \\
\hline$\$ 90-99,999$ & 2 & $2.6 \%$ & 2 & $5.3 \%$ & 0 & $0.0 \%$ \\
\hline$>\$ 100,000$ & 15 & $19.7 \%$ & 6 & $15.8 \%$ & 9 & $23.7 \%$ \\
\hline \multicolumn{7}{|l|}{ Currently in a Relationship? } \\
\hline Yes and cohabiting & 30 & $39.5 \%$ & 13 & $34.2 \%$ & 17 & $44.7 \%$ \\
\hline Yes but not cohabiting & 18 & $23.7 \%$ & 9 & $23.7 \%$ & 9 & $23.7 \%$ \\
\hline No & 28 & $36.8 \%$ & 16 & $42.1 \%$ & 12 & $31.6 \%$ \\
\hline
\end{tabular}


Online Table S2

Median, Mean, Standard Deviation, and Cronbach's Alphas for Measures

\begin{tabular}{|c|c|c|c|c|c|c|c|c|c|c|c|c|c|}
\hline & \multirow{2}{*}{$\begin{array}{l}\text { Possible } \\
\text { Range }\end{array}$} & \multicolumn{4}{|c|}{$\begin{array}{c}\text { Whole Sample } \\
\quad N=76\end{array}$} & \multicolumn{4}{|c|}{$\begin{array}{c}\text { Gay } \\
n=38\end{array}$} & \multicolumn{4}{|c|}{$\begin{array}{c}\text { Heterosexual } \\
n=38\end{array}$} \\
\hline & & $M d n$ & $M$ & $S D$ & $\alpha$ & $M d n$ & $M$ & $S D$ & $\alpha$ & $M d n$ & $M$ & $S D$ & $\alpha$ \\
\hline \multicolumn{14}{|l|}{ SCL-90-R Dimensions } \\
\hline Somatization & $0.00-4.00$ & 0.34 & 0.47 & 0.43 & .77 & 0.34 & 0.41 & 0.31 & .51 & 0.34 & 0.53 & 0.53 & .85 \\
\hline Obsessive-Compulsive & $0.00-4.00$ & 0.71 & 0.91 & 0.71 & .87 & 0.61 & 0.80 & 0.64 & .84 & 0.81 & 1.02 & 0.76 & .89 \\
\hline Interpersonal Sensitivity & $0.00-4.00$ & 0.45 & 0.64 & 0.56 & .81 & 0.39 & 0.57 & 0.50 & .78 & 0.45 & 0.71 & 0.61 & .84 \\
\hline Depression & $0.00-4.00$ & 0.54 & 0.74 & 0.55 & .84 & 0.54 & 0.71 & 0.50 & .79 & 0.54 & 0.78 & 0.60 & .88 \\
\hline Anxiety & $0.00-4.00$ & 0.31 & 0.47 & 0.52 & .85 & 0.31 & 0.39 & 0.43 & .79 & 0.46 & 0.56 & 0.59 & .88 \\
\hline Hostility & $0.00-4.00$ & 0.34 & 0.45 & 0.59 & .86 & 0.26 & 0.30 & 0.34 & .64 & 0.34 & 0.61 & 0.73 & .90 \\
\hline Phobic Anxiety & $0.00-4.00$ & 0.01 & 0.14 & 0.29 & .77 & 0.01 & 0.15 & 0.35 & .86 & 0.01 & 0.14 & 0.23 & .56 \\
\hline Paranoid Ideation & $0.00-4.00$ & 0.34 & 0.56 & 0.60 & .73 & 0.34 & 0.42 & 0.41 & .49 & 0.42 & 0.71 & 0.72 & .80 \\
\hline Psychoticism & $0.00-4.00$ & 0.21 & 0.38 & 0.46 & .79 & 0.11 & 0.26 & 0.28 & .57 & 0.26 & 0.49 & 0.57 & .83 \\
\hline \multicolumn{14}{|l|}{ SCL-90-R Indices } \\
\hline Global Severity & $0.00-4.00$ & 0.47 & 0.57 & 0.42 & .96 & 0.46 & 0.49 & 0.31 & .93 & 0.53 & 0.65 & 0.51 & .97 \\
\hline Positive Symptom Distress & $0.00-4.00$ & 1.44 & 1.53 & 0.39 & - & 1.44 & 1.54 & 0.36 & - & 1.44 & 1.53 & 0.42 & - \\
\hline Positive Symptom Total & $0-90$ & 31.50 & 30.92 & 6.26 & - & 24.50 & 27.34 & 14.14 & - & 33.50 & 34.50 & 21.32 & - \\
\hline Positive Help-Seeking Attitude & $0-30$ & 20.00 & 19.68 & 6.26 & .86 & 22.00 & 21.13 & 5.73 & .84 & 19.50 & 18.24 & 6.51 & .86 \\
\hline GRCS Total Score & $37-222$ & 118.00 & 119.29 & 26.52 & .91 & 114.00 & 114.79 & 29.08 & .93 & 121.50 & 123.79 & 23.20 & .88 \\
\hline $\begin{array}{l}\text { Success, Power, \& } \\
\text { Competition }\end{array}$ & $13-78$ & 50.00 & 47.75 & 12.64 & .89 & 50.00 & 48.08 & 12.68 & .89 & 50.00 & 47.42 & 12.76 & .89 \\
\hline Restricted Emotions & $10-60$ & 28.50 & 29.75 & 11.02 & .90 & 28.00 & 29.03 & 11.99 & .92 & 28.50 & 30.47 & 10.07 & .89 \\
\hline Restricted Affection & $8-48$ & 20.00 & 20.64 & 7.05 & .78 & 16.50 & 16.97 & 4.97 & .71 & 24.00 & 24.32 & 6.95 & .78 \\
\hline Work/School Emphasis & $6-36$ & 22.00 & 21.14 & 7.46 & .86 & 21.50 & 20.71 & 7.98 & .89 & 22.00 & 21.58 & 6.98 & .83 \\
\hline
\end{tabular}

Note. SCL-90-R (Symptom Checklist-90-Revised) statistics are based on the raw scores. GRCS = Gender Role Conflict Scale. 